\title{
Self-management in women with stress incontinence: strategies, outcomes and integration into clinical care
}

This article was published in the following Dove Press journal:

Research and Reports in Urology

\author{
Sarah C Titman' \\ Stephen C Radley ${ }^{2}$ \\ Thomas G Gray ${ }^{2}$ \\ 'Community Continence Service, \\ Sheffield Teaching Hospitals NHS \\ Foundation Trust, Sheffield, UK; \\ ${ }^{2}$ Urogynaecology Unit, Sheffield Teaching \\ Hospitals NHS Trust, Sheffield, UK
}

\begin{abstract}
The objective of this review is to present and discuss up-to-date conservative treatment strategies for the management of stress urinary incontinence (SUI) in women. This review aims to provide an overview of the importance of initial self-management strategies and conservative management options for women with SUI and how these treatments can be integrated into clinical practice. The various treatment modalities available including pelvic floor physiotherapy, biofeedback, and neuromuscular electrical stimulation devices, in addition to lifestyle changes which can significantly affect symptoms, are discussed. The relevance and importance of individual assessment and training programs is highlighted in addition to additional adjuncts available to facilitate rehabilitation and symptom improvement. Expected outcomes for women with mild to moderate SUI who participate in targeted individualized conservative management programs are generally good, with a high likelihood of substantial improvement in symptoms.
\end{abstract}

Keywords: urinary incontinence, stress, pelvic floor disorders, physical therapy modalities

\section{Introduction}

Stress urinary incontinence (SUI) is defined by the International Continence Society (ICS) as "the complaint of any involuntary loss of urine on effort or physical exertion (eg, sporting activities) or on sneezing or coughing." ${ }^{\text {, }}$ SUI affects women worldwide and can a significant impact on lifestyle and quality of life, including social interaction, exercise participation, wellbeing and mood..$^{2-4}$ It has been estimated to affect between 13 and $46 \%$ of women across Northern Europe and Australia., 5any women accept symptoms of urinary incontinence as "normal" and may suffer with symptoms for many years or not seek help unless symptoms deteriorate. ${ }^{7}$ This is often due to social stigma around incontinence, embarrassment, reinforced by beliefs that SUI is a normal part of ageing. ${ }^{4}$ Prevalence of SUI increases with age, parity, obesity and presence of diabetes. ${ }^{8-10}$ Effective management strategies and education can prevent onset or progression of SUI, with a positive effect on both quality of life and financial implications for health care providers.

Symptoms of SUI may be due to weakness of the pelvic floor muscles (PFM) in supporting the closure of urethral sphincters, fascial or ligamentous damage following trauma, most commonly occurring during childbirth ${ }^{11,12}$ or due to dysfunction of neuromuscular components that manage pressure change. ${ }^{13}$ During a PFM contraction the levator muscles move inwards. ${ }^{2}$ Improvements in motor patterning, localized pelvic floor muscle hypertrophy and timing of muscle activation can be gained through regular pelvic floor muscle exercises, with the purpose of improving
Correspondence: Sarah Titman

Community Continence Service, Manor

Clinic, Ridgeway Road, Sheffield SI2 2ST, UK

Tel +44 II4 27I 3248

Email sarah.titman@nhs.net 
urethral closure and preventing downward pressure on the bladder neck. ${ }^{12-15} \mathrm{Bø}$ (2004) proposed that specific pelvic floor muscle training (PFMT) may "lift" the levator plate to a higher position by increasing muscle volume. Conservative management, including PFMT is recommended as first line intervention prior to consideration for surgery for mild to moderate SUI. ${ }^{16}$ In this review we will discuss the role of conservative management of SUI, including strategies for self-management, lifestyle changes, the role of PFMT, including the use of electrostimulation and biofeedback and intravaginal devices.

\section{Strategies of self-management for SUI in women}

It is understood that the time between onset of SUI symptoms and seeking help from a medical professional can be significant; this is likely to be due in part to a lack of awareness of services or treatment available and difficulty in accessing help. ${ }^{4}$ Therefore ensuring awareness and ease of access to local health care professionals specializing in the management of SUI and other bladder symptoms is vital. This could be achieved through health care professionals having conversations with patients within local community settings and interventions at times of known changes to the pelvic floor, for example, during and immediately following childbirth, pelvic surgery or at the time of the menopause. Use of standardized validated questionnaires in these settings can aid the identification of stress incontinence and help to initiate discussions and treatments. ${ }^{17}$ Screening and early identification of pelvic floor dysfunction could aid in more timely and appropriate access to self-management options and support. PFM training during and after pregnancy is known to have a positive impact on SUI up to one year postpartum for women who are incontinent following childbirth; information and education is routinely provided to women during this time within the UK. ${ }^{17,18}$

Lifestyle factors known to affect the onset and continued presence of SUI include obesity, smoking and constipation. It has been reported that a $20-70 \%$ increased risk of urinary incontinence is associated with an increase of five points on recorded body mass index (BMI). ${ }^{19}$ Obesity is a known independent risk factor for $\mathrm{SUI}^{10}$ and therefore supporting women to lose any excess weight can significantly improve urinary incontinence. There is also evidence that bariatric surgery has significant beneficial effects on SUI. In a cohort of 366 women undergoing bariatric surgery, cure rates of $41 \%$ for SUI were reported at 12 months. ${ }^{19}$ Whilst not an appropriate treatment for all obese patients, the benefits of bariatric surgery on pelvic floor symptoms are proven.

Smoking has also been highlighted as a contributing factor towards SUI, mainly due to excessive coughing or contribution towards chronic respiratory disease; although prevalence is greater with those smoking more than 20 cigarettes per day. ${ }^{20}$ Smoking cessation should be recommended to patients with SUI and referral to community smoking cessation services which can provide cognitive support and nicotine replacement therapy is recommended. Vaping is increasingly recognized as an important adjunct in smoking cessation and is almost certainly less harmful than smoking tobacco. A switch to vaping may result in a beneficial effect on SUI due to reduced coughing, but there is currently no evidence for this and patients should be informed that we are unaware of the long-term risks of vaping.

\section{Integration of PFMT into clinical care}

PFMT compared with no treatment is well researched and has significantly beneficial effects on improving continence specific outcome measures and overall quality of life..$^{4,13,21,22}$ In a recent large scale Cochrane systematic review including 31 trials involving 1,817 women, Dumoulin et al (2018) found that women were eight times more likely to report a cure in symptoms of SUI with PFMT than with no active treatment. The rationale behind PFMT is to build PFM strength, muscle bulk, endurance and timing of muscle contraction to resist downward movement with rises in intra-abdominal pressure. $^{2,9,13}$ Table 1 provides a summary of randomized controlled trials and systematic reviews assessing the effectiveness of PMFT for SUI.

The National Institute for Clinical Excellence (NICE) within the $\mathrm{UK}^{16}$ recommends digital assessment of PFM activation prior to supervized PFM training to assess effective muscle activation; this should be part of a thorough subjective and objective assessment and is usually assessed using the modified Oxford score (Table 2). This assessment can be applied at baseline and used to monitor progress with treatment. It has been shown through transperineal ultrasound studies and manual muscle testing that some women depress instead of elevate their bladder neck on voluntary pelvic floor 


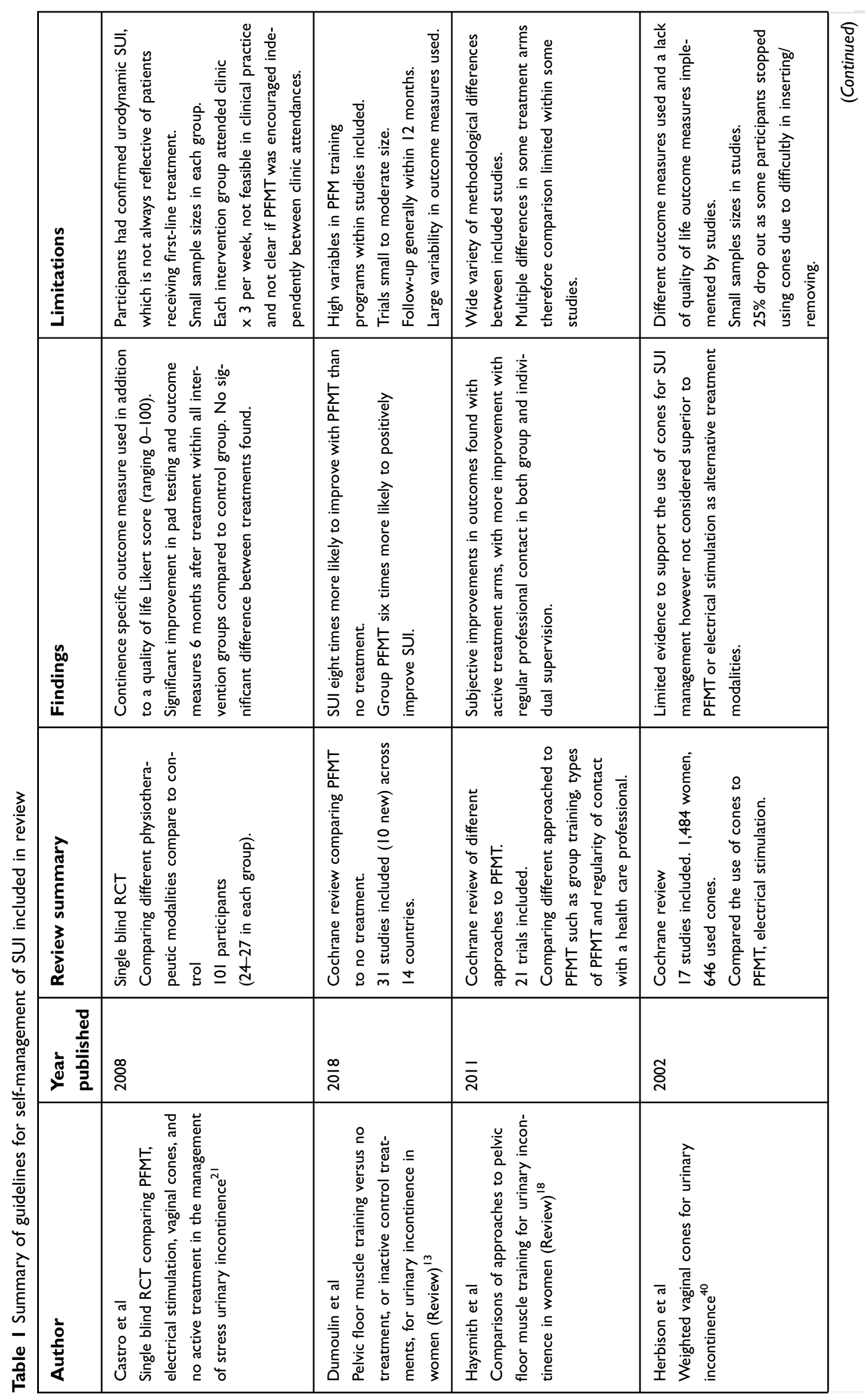




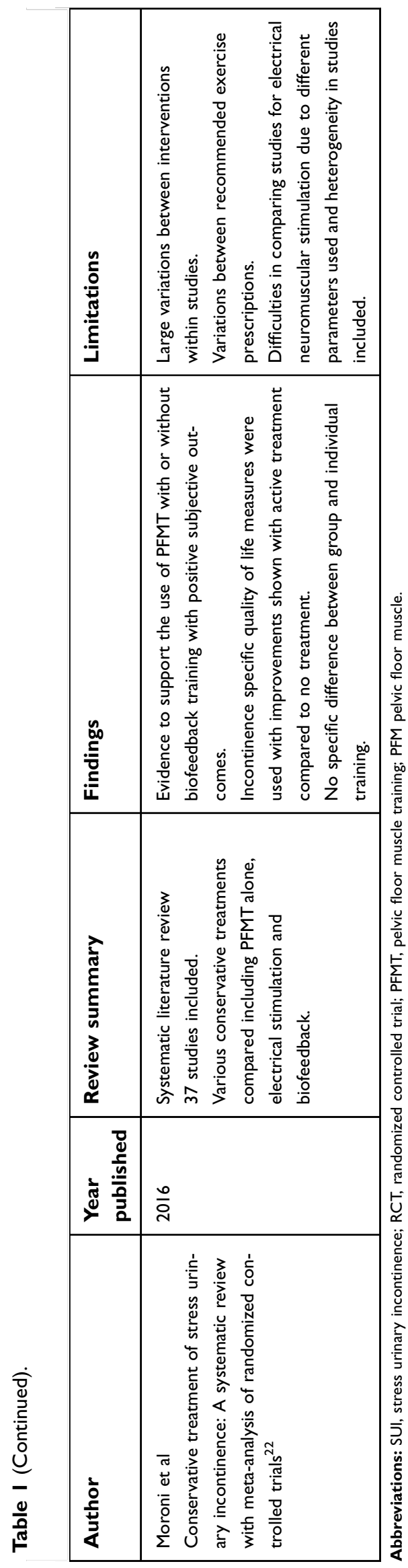

Table 2 Modified Oxford grading score

\begin{tabular}{|l|l|}
\hline Numerical scale & Evaluation of strength \\
\hline 0 & No contraction \\
1 & Flicker \\
2 & Weak \\
3 & Moderate \\
4 & Good (with lift) \\
5 & Strong \\
\hline
\end{tabular}

muscle contraction when undertaking self-directed PFM exercises. $^{23,24}$ In a previous study, which combined a mixture of continent and incontinent women $(17 \%$ and $30 \%$ respectively), $23 \%$ of 60 participants demonstrated this. ${ }^{24}$ This helps to highlight the importance of supervized pelvic floor muscle assessment in order to detect strength, endurance and also technique of PFM activation, in addition to direction of muscle contraction against the bladder neck to optimally reduce SUI. It is not possible for patients to self-direct their treatment in this way simply from information sheets, although this is often the standard practice in primary care. Once correct technique has been achieved then progression to focused PFMT can be undertaken in addition to more global postural and function specific rehabilitation. PFM endurance has been found to be significantly different between continent and incontinent women. ${ }^{24}$ It is therefore recommended that PFMT includes both fast and slow twitch muscle training to optimize continence.

Effective PFM strength and contraction by manual muscle testing has positive correlations with bladder neck elevation on ultrasound measurements. ${ }^{24}$ This highlights the benefit of ensuring correct technique during rehabilitation. Specialist women's health/pelvic health physiotherapists are best placed to assess and treat women suffering with SUI in a variety of health care settings. These specialist physiotherapists have postgraduate training and expertize in digital pelvic floor muscle testing and in some settings, access to equipment such as real-time ultrasound to aid with assessment and rehabilitation. This is in addition to an understanding of the role of the pelvic floor as part of the core muscular and dynamic system in optimally managing intra-abdominal pressure.

Once effective and isolated PFM activation is achieved, a specific training program can be devised. This would include specified duration of muscle contraction followed by timed relaxation, determining effort required during activation (eg, maximal or sub-maximal) and the length of expected training program required for 
Table 3 PERFECT score ${ }^{26}$

\begin{tabular}{|l|l|l|}
\hline $\mathbf{P}$ & Power & $\begin{array}{l}\text { Strength of MVC, measured by } \\
\text { the modified Oxford grading } \\
(\mathbf{0}-\mathbf{5})\end{array}$ \\
\hline E & Endurance & $\begin{array}{l}\text { Length of MVC (before strength is } \\
\text { reduced by 35\% or more) } \\
\text { Repetition of endurance hold } \\
\text { Number of fast contractions }\end{array}$ \\
F & $\begin{array}{l}\text { Repetitions } \\
\text { Fast } \\
\text { ECT } \\
\text { Everyactions } \\
\text { Contraction, } \\
\text { Timed }\end{array}$ & \\
\hline
\end{tabular}

Abbreviation: MVC, maximal voluntary contraction.

symptom relief on an individual basis. ${ }^{25}$ This can be confirmed by PFM testing as discussed and the use of individualized assessment scores including the modified Oxford grading score (power 0-5) and also the commonly used tool, the PERFECT score (power, endurance, repetitions, fast, every contraction timed) (Table 3) which was introduced to simplify pelvic floor assessments and aid with more individualized muscle training programs. ${ }^{26,36}$ These systems give measurements of muscle power to assess change and the PERFECT score was refined in 2008 to include elevation of muscle activation, co-activation of other supporting muscles and timing contraction; although it should be noted that this progression has not been tested for validity or reliability.

\section{Different types of PFMT}

Training programs including length, repetition and intensity of training should follow general muscle training principles applied to effect muscle hypertrophy and coordinated contraction with an aim to better manage changes in pressure. ${ }^{27,28}$ Many researchers have compared the optimal number of PFM exercises, combining strength and endurance training. Dumoulin et al (2018) summarize variations in practice within their extensive systematic review. Thirty-one studies were included, with variable sample sizes (15-143 participants) and program content. Exercise prescription generally included endurance and strength based exercises. Endurance holds varied from six to 30 seconds and fast contractions lasted from 1-3 seconds. These were recommended within sets of one per day, three per day or as a program three times per week, it is therefore difficult to compare training programs between studies included and draw definitive conclusions. Fourteen more recent studies in the review included programs which were progressive with increasing length of muscle activation and number of repetitions based on PFM assessment and were progressed over time following reassessment; this is more typical of current clinical practice. ${ }^{13}$

Despite variation across study designs, national UK guidelines for PFMT as recommended by NICE (2015) suggest undertaking eight contractions three times per day over a three-month period to assess effects of muscle training on symptom profile. The American College of Sports Medicine (ACSM) (2009) recommend 8-12 repetitions with a $2-10 \%$ progression for general strength training and $>15$ repetitions of light loads with short rest periods for endurance training. These muscle training principles can also be applied to the pelvic floor to address slow and fast twitch muscle fibers by increasing the intensity of contraction with and against gravity to progress strength (fast twitch) and undertaking high repetitions of low loads with submaximal contraction for endurance (slow twitch). ${ }^{13}$

Once effective muscle activation is achieved, it is possible for women to continue with regular, selfdirected exercise programs in addition to regular appointments with their health care provider, or in some settings in addition to regular exercise classes (eg, once per week). PFMT in addition to supervised weekly groups sessions have been found to improve reported self-satisfaction with SUI symptoms over a 6-month period. ${ }^{29}$ Ferreira et al (2013) compared group training with completion of a home exercise program alone, although both groups improved and sample size was small. Haysmith et al (2011) undertook a large review comparing approaches to PFM training for SUI in women. The amount and type of training supervision, eg, individual or group interaction, the type and frequency of training and the approach of training, eg, specific PFM exercise or the addition of lower limb or core exercises varied between groups; the results were therefore difficult to compare. The study's main finding was self-reported improvement of SUI with both individual and group intervention; however, the main factor was the relevance of regular contact with a health care professional rather than the type of contact provided.

Despite the physiological and neuromuscular changes that rehabilitation aims to improve for symptom reduction, the significance of patient quality of life, effect on selfesteem, and individual wellbeing should be regularly recorded within clinical practice using validated quality of life measures and must always be recognized when 
treating individuals suffering with SUI. ${ }^{30}$ Regular contact with a clinician, group PFM exercise or education classes can provide emotional support and networks in which women feel less isolated and more empowered about managing their symptoms in a positive way.

\section{Functional integration of PFMT into daily activities}

$\mathrm{B} \varnothing$ (2004) identified a delay in or lack of reflex PFM contraction in women with urinary incontinence with a rise in intra-abdominal pressure. Research into timing of PFM activation prior to tasks or activities known to increase pressure, specifically coughing, have been investigated with positive results in controlling SUI. ${ }^{31}$ This can be taught within clinical practice to preempt provocative activities and improve continence mechanisms for more daily tasks. ${ }^{32}$ This could also be used for functional and more dynamic tasks, such as lifting, pushing or pulling a load by integrating pelvic floor and surrounding skeletal muscles to counteract pressure change. PFM activation occurs automatically in continent subjects ${ }^{33}$ and rehabilitation aims to assist with this process by building PFM strength, size and position to be able to do this. In addition to selective PFM strengthening it can also be beneficial to strengthen local pelvic muscles and hip stabilizers. Gluteals and hip adductors have been found to work synergistically with the $\mathrm{PFM}^{33,34}$ and PFM also found to be active during voluntary activation of deep abdominal muscles. ${ }^{35}$ Individual holistic assessment and treatment targeting the pelvic region as a whole can provide better control and it could be argued better awareness and accessibility to the PFM for functional activities; evidence within this area is ongoing.

\section{Biofeedback during PFMT}

Biofeedback is the process of gaining greater awareness of a physiological function (in this case PFM contraction) primarily using instruments that provide information on the activity of those same systems, with a goal of the patient then being able to contract their pelvic floor at will. Biofeedback can be used as a behavioural treatment and adjunct for muscle training and motor re-learning for the management of SUI. The simplest form of biofeedback is verbal feedback from digital palpation to confirm effective contraction $^{36-38}$ Biofeedback can help patients to learn to respond to visual and/or auditory stimulus produced mainly by internal pressure or electromyography (EMG) biofeedback, which uses surface electrodes to detect skeletal muscle changes on contraction or relaxation of the PFM (Figure 1). This can be used alongside real-time ultrasound, which provides visual feedback and is being used more routinely by physiotherapists for muscle re-training as a noninvasive option. ${ }^{24}$ This information can then be used to coordinate timing and aid effective muscle contraction prior to changes in intra-abdominal pressure, building strength and providing feedback for muscle relaxation; in addition to increasing motivation and exercise adherence. ${ }^{38}$ There are a large variety of biofeedback devices available to purchase by patients independently for home use and for clinicians within clinic settings. Devices have recently become more sophisticated to assess vaginal pressure changes in addition to direction of muscle activation to ensure that valsalva manoeuvres are not undertaken.

Mørkved et al (2002) and Moroni et al (2016) found that there were no significant benefits to incorporating biofeedback into usual PFMT in women who can effectively contract their PFM. However, for some patients the ability to visualize correct activation is extremely beneficial in motor re-learning and neuromuscular control and therefore within clinical practice biofeedback can be a useful additional adjunct to treatment.

\section{Intravaginal neuromuscular electrical stimulation as an adjunct to PFMT}

Intravaginal neuromuscular electrical stimulation (NMES) aims to improve PFM power and contractibility by producing a series of electrical impulses to aid with muscle contractibility and strength. ${ }^{36} \mathrm{~A}$ vaginal probe with electrode attachment is used (Figure 2) and patient participation encouraged with maximum patient controlled current intensity to elicit a contraction. Treatment time varies between individuals to begin with, optimal time of 20 minutes achieved once daily.

Evidence is conflicting in regards to the use of NMES in improving SUI symptoms and it has not been found to be superior to PFMT alone. ${ }^{21,39}$ NICE (2015) do not advise its use in routine PFM rehabilitation. However, the inclusion of electrical stimulation needs to be considered on an individual basis dependent on clinical findings, especially for those who are unable to voluntarily activate their PFM effectively; where it may provide a basis for treatment. 


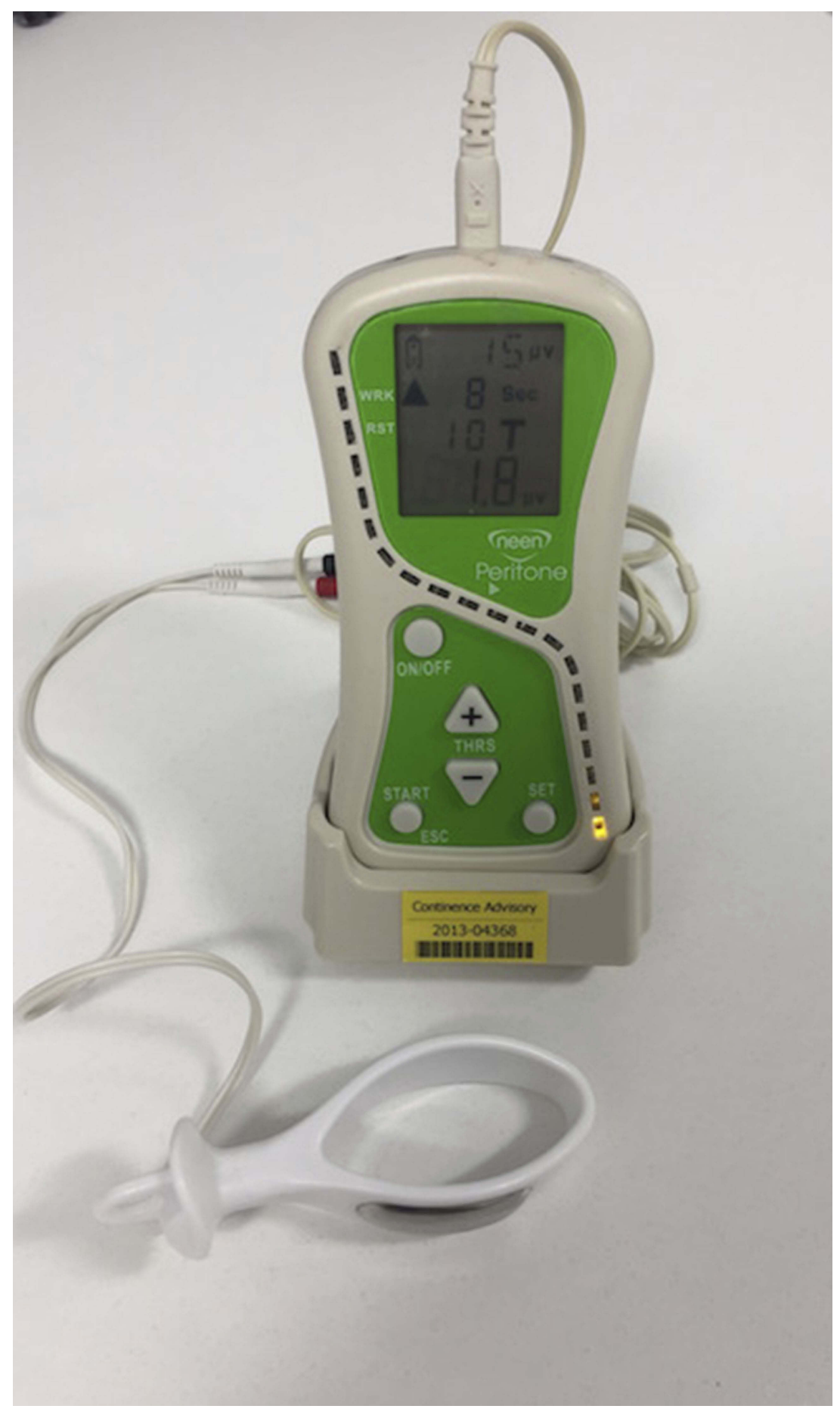

Figure I Neen Peritone ${ }^{T M}$ Biofeedback device used to provide biofeedback on the effectiveness of pelvic floor muscle activation.

\section{Vaginal cones}

Vaginal cones are weighted cone-shaped plastic tampons, designed to support pelvic muscle training. The heavier the cone, the more effectively a patient needs to recruit their pelvic floor in order to prevent the cone from falling out. It is proposed that vaginal cones can aid with a contraction of pelvic floor musculature to retrain muscle strength. $^{36 .}$ The cones are designed to stay within the vagina during functional tasks for 10-20 minutes. ${ }^{40}$

A Cochrane review found that weighted vaginal cones are better than no active treatment but no better than PFMT and NMES for women with symptoms of SUI. ${ }^{40}$ Few studies were included within the review with small sample sizes noted; however as an additional conservative 


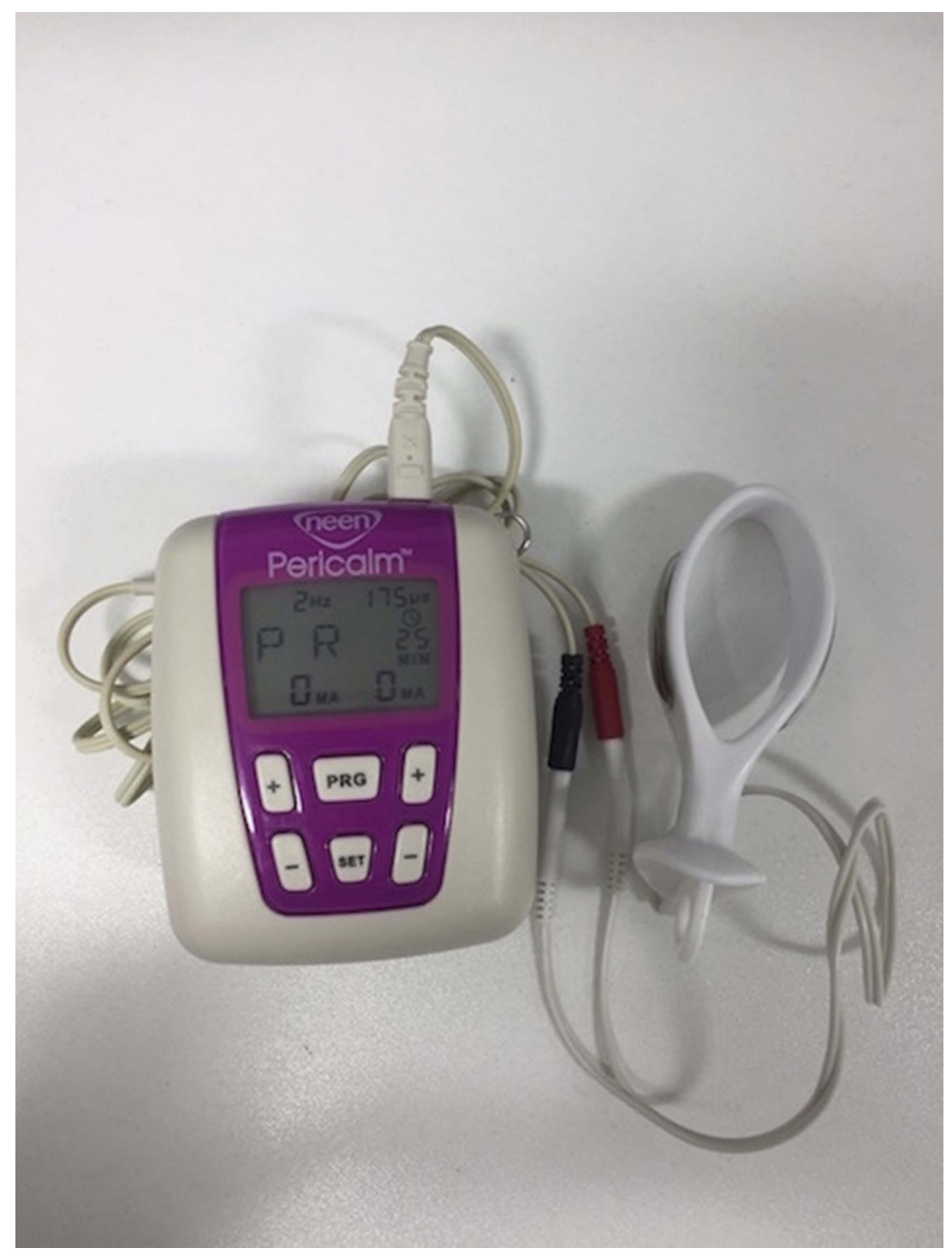

Figure 2 Neen Pericalm ${ }^{\mathrm{TM}}$ neuro-muscular electrical stimulation kit.

Note: The probe on the right is inserted into the vagina and provides electrical stimulation to provoke pelvic floor muscle contraction to aid power and contractility of the pelvic floor as part of a pelvic floor muscle training regime.

method, cones could be an option for some women and many different types are available on the market.

\section{Comparing conservative treatment modalities}

Conservative treatment methods have been compared in studies with variable results. It is agreed that active intervention in the form of pelvic floor muscle training, intravaginal stimulation and vaginal cones can all positively affect pelvic floor function and overall frequency and severity of SUI. ${ }^{21}$ A single-blind randomized control trial by Castro et al (2008) demonstrated significant improvements in pad testing for provoked SUI, improved quality of life and reported frequency of leakages in all active treatment arms (pelvic floor muscle training, intravaginal stimulation and vaginal cones) compared with no active treatment. However, no significant differences were found between active treatment arms, except for significant improvements in muscle grading in the PFMT group. The study authors, in addition to NICE (2015), recommend supervized PFMT as first-line intervention, with considerations to add intravaginal stimulation and vaginal cones if patients are unable to contract their PFM effectively, but not used as routine first-line treatment.

\section{Intravaginal devices}

For some women, if pelvic floor training has improved overall strength, endurance and power but symptoms of 


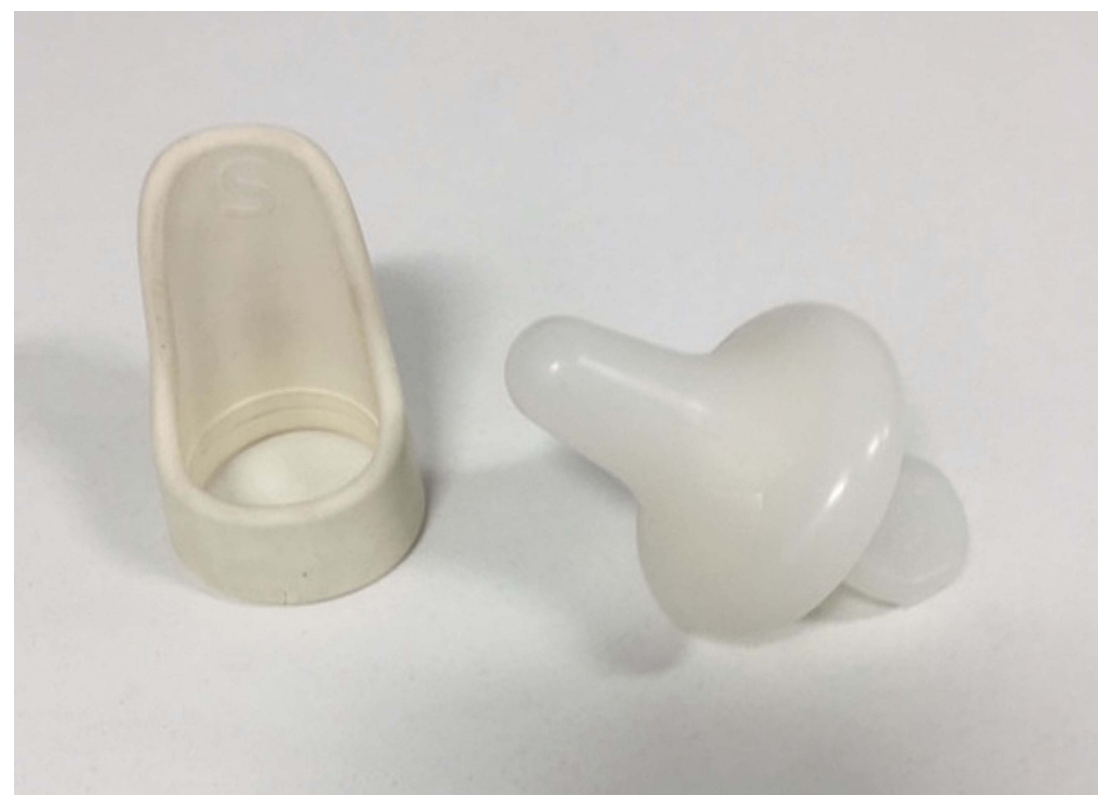

Figure 3 An example of two of the many intravaginal devices designed to reduce stress urinary incontinence. Contiform ${ }^{\mathrm{TM}}$ (left) Uresta ${ }^{\mathrm{TM}}$ (right). Note: Contiform ${ }^{\mathrm{TM}}$ (left); Uresta ${ }^{\mathrm{TM}}$ (right).

SUI persist in association with high-impact exercise, then in some cases an intravaginal device (Figure 3) may be useful to support the bladder neck in addition to previous strategies discussed. ${ }^{2}$ These can be used at the time of exercise or other activities which provoke stress incontinence, providing internal support, reducing leakage and enhancing confidence and participation in physical activity and may be used as a long-term adjunct to manage SUI. Such devices include ring pessaries with an anterior protrusion, which supports the urethra, or devices such as Contiform $^{\mathrm{TM}}$ vaginal pessary which is cylindrical or Uresta $^{\mathrm{TM}}$ (see Figure 3). Evidence for the use of intravaginal devices is limited, some patients find these devices effective and use them in the long-term having derived significant benefit, and others find them uncomfortable or undignified and do not use them.

\section{Technological support}

It is recognized that supervized PFMT is superior to home PFMT in regards to subjective improvement ${ }^{22}$ and pad testing, ${ }^{41}$ however, in some situations such as remote distances from a clinician or an inability to travel, this maybe a beneficial option as a self-management strategy. Preliminary studies looking into web-based programs with video description and instructions on correct pelvic floor muscle activation have been used previously with positive outcomes, despite small sample sizes. ${ }^{42}$ The aims of this type of learning are to aid with exercise compliance, provide information to support treatment and could be an initial contact to prompt seeking further help. It could also be used as an additional tool to aid with motivation following an initial consultation with a specialist physiotherapist. Such forms of support have been successfully devised internationally with downloadable "Apps" onto digital mobile phones. Whilst there is limited evidence for the efficacy and utility of Apps which aid PMFT, many patients express an interest in using these tools. The most widely used App in the UK is Squeezy ${ }^{\mathrm{TM}}$ which has been recommended for use by the NHS App library. ${ }^{43}$

\section{Conclusion}

Expected outcomes for women with mild to moderate SUI who participate in targeted individualized training programs are very good, with a high likelihood of significant improvement or cure of symptoms. ${ }^{13}$ Maintaining a healthy BMI and making positive lifestyle choices are also very important. There are many adjuncts and training devices available for individuals to use to self-manage SUI, however, if taught effective PFM activation with regular contact from a specialist health care provider, patients are more likely to have better long-term outcomes with SUI. Clinical guidelines within the $\mathrm{UK}^{16}$ recommend a trial of supervized pelvic floor training prior to surgical intervention or more invasive procedures. It could be argued that the most important selfmanagement strategy is empowerment of women to seek 
appropriate help from an early stage. It is known that outcomes are better for mild to moderate SUI with conservative treatment and self-management strategies, therefore timely access to relevant information can be significant to improving quality of life and reduce symptom severity and progression.

\section{Disclosure}

Professor Stephen Radley is the Director and shareholder in ePAQ Systems Ltd, an NHS Spin-out Technology Company. The authors report no other conflicts of interest in this work.

\section{References}

1. Haylen, B, De Ridder, D, Freeman, RM.et al. An International Urogynecological Association (IUGA)/International Continence Society (ICS) Joint Report on the Terminology for Female Pelvic Floor Dysfunction. J Neurourol Urodyn. 2010;29:4-20.

2. Bø K. Urinary incontinence, pelvic floor dysfunction, exercise and sport. Sports Med. 2004;34:451-464. doi:10.2165/00007256200434070-00004

3. Donahoe-Fillmore B, Chorny W, Brahler J, Ingley A, Kennedy J, Osterfeld V. A comparison of two pelvic floor muscle training programs in females with stress urinary incontinence: a pilot study. $J$ Appl Res. 2011;2:73-83.

4. Lukacz E, Sampselle C, Gray M, et al. A healthy bladder: a consensus statement. Int J Clin Pract. 2011;65(10):1026-1036. doi:10.1111/j.1742-1241.2011.02763.x

5. Botlero R, Urquhart D, Davis S, Bell R. Review of the literature and investigation of methodological issues. Int J Urol. 2008;15:230-234.

6. Hunskaar S, Lose G, Sykes D, Voss S. The prevalence of urinary incontinence in women in four European countries. BJU Int. 2004;3:324-330.

7. Seim A, Sandvik H, Hermstad R, Hunskaar S. Female urinary incontinence - consultation behaviour and patient experiences: an epidemiological survey in a Norwegian community family planning. Fam Pract. 1995;12(1):18-21.

8. Angler J, Saigal C, Litwin M. The prevalence of urinary incontinence among community dwelling adult women: results from the national health and nutrition examination survey. $J$ Urol. 2006;175:601-604. doi:10.1016/S0022-5347(05)00697-X

9. Izak Faiena I, Neal Patel N, Parihar S, Calabrese MD, Tunuguntla H. Conservative management of urinary incontinence in women. Rev Urol. 2015;17:129-139.

10. Townsend MK, Danforth KN, Rosner B, Curhan GC, Resnick NM, Grodstein F. Body mass index, weight gain, and incident urinary incontinence in middle-aged women. Obstet Gynecol. 2007;110(2 Pt 1):346-353. doi:10.1097/01. AOG.0000270121.15510.57

11. Hung H, Hsiao S, Chih S, Lin H, Tsauo J. Effect of pelvic-floor muscle strengthening on bladder neck mobility: a clinical trial. Phys Ther. 2011;7:1030-1038. doi:10.2522/ptj.20100186

12. Laycock J, Standley A, Crothers E, et al. Clinical guidelines for the Physiotherapy Management of Females aged 16-65 with Stress Urinary Incontinence. London: Chartered Society of Physiotherapy; 2001.

13. Dumoulin C, Cacciari LP, Hay-Smith J. Pelvic floor muscle training versus no treatment, or inactive control treatments, for urinary incontinence in women (Review). Cochrane Database Syst Rev. 2018; (Issue 10). doi:10.1002/14651858.CD005654.pub4
14. Dumoulin C, Hay-Smith J. Pelvic floor muscle training versus no treatment, or inactive control treatments, for urinary incontinence in women (Review). Cochrane Database Syst Rev. 2010;(Issue 1). doi:10.1002/14651858.CD005654.pub2

15. Fellicissimo M, Carneiro M, Saleme C, Pinto R, da Fonseca A, da Silva-Filho A. Intensive supervised versus unsupervised pelvic floor muscle training for the treatment of stress urinary incontinence: a randomised comparative trial. Int Urogynecol J. 2010;21:835-840.

16. NICE National Institute for Health and Clinical Excellence. Urinary Incontinence: the management of urinary incontinence in women. NICE Clin Guideline. 2015;171. Available from: www.nice.org.uk/guidance/ cg171. Accessed March 29, 2019.

17. Schüssler-Fiorenza Rose SM, Gangnon RE, Chewning B, Wald A. Increasing discussion rates of incontinence in primary care: a randomized controlled trial. $J$ Womens Health. 2015;24 (11):940-949. doi:10.1089/jwh.2015.5230

18. Hay-Smith E, Morkved S, Fairbrother K, Herbison G. Pelvic floor muscle training for prevention and treatment of urinary and faecal incontinence in antenatal and postnatal women. Cochrane Database Syst Rev. 2008. doi:10.1002/14651858.CD007471

19. Anglim B, O’Boyle CJ, O’Sullivan OE, O'Reilly BA. The long-term effects of bariatric surgery on female urinary incontinence. Eur J Obstet Gynecol Reprod Biol. 2018;231:15-18. doi:10.1016/j. ejogrb.2018.10.011

20. Hannestad Y, Rortveit G, Kjersti Daltveit A, Hunskaar S. Are smoking and other lifestyle factors associated with female urinary incontinence? The Norwegian EPINCONT study. BJOG. 2003;110:247-254. doi:10.1046/j.1471-0528.2003.02327.x

21. Castro R, Arruda R, Zanetti M, Santos P, Sartori M, Girão M. Singleblind, randomized, controlled trial of pelvic floor muscle training, electrical stimulation, vaginal cones, and no active treatment in the management of stress urinary incontinence. Clinics. 2008;63:465-472.

22. Moroni R, Magnani P, Haddad J, Castro R, Brito L. Conservative treatment of stress urinary incontinence: a systematic review with meat-analysis of randomized controlled trials RBGO. Gynaecol Obstet. 2016;38:97-111.

23. Bump R, Hurt W, Fantl J, Wyman J. Assessment of Kegel exercise performance after brief verbal instruction. Am J Obstet Gynecol. 1991;165:322-329.

24. Thompson J, O'Sullivan P, Briffa K, Nuumann P. Assessment of voluntary pelvic floor muscle contraction in continent and incontinent women using transperineal ultrasound, manual muscle testing and vaginal squeeze pressure managements. Int Urogynecol $J$. 2006;17:624-630. doi:10.1007/s00192-006-0081-2

25. Hay-Smith E, Herderschee R, Dumoulin C, Herbison G. Comparisons of approaches to pelvic floor muscle training for urinary incontinence in women (Review). Cochrane Lib. 2011;(issue 12). doi:10.1002/14651858.CD00950

26. Laycock J, Jerwood D. Pelvic Floor Muscle Assessment: the PERFECT scheme. Physiotherapy. 2001;87(12):631-642. doi:10.1016/S00319406(05)61108-X

27. ACSM. Progression models in resistance training for healthy adults. Med Sci Sports Exerc. 2009;41:687-708.

28. Garber CE, Blissmer B, Deschenes MR, et al. American College of Sports Medicine position stand. Quantity and quality of exercise for developing and maintaining cardiorespiratory, musculoskeletal, and neuromotor fitness in apparently healthy adults: guidance for prescribing exercise. Med Sci Sports Exerc. 2011;43:1334-1359. doi:10.1249/MSS.0b013e318213fefb

29. Ferreira M, Santos P, Duarte J, Rodrigues R. Exercise programmes for women with stress urinary incontinence. Primary Health Care. 2012;3:24-27. doi:10.7748/phc2012.04.22.3.24.c9021

30. Sinclair A, Ramsay I. The psychosocial impact of urinary incontinence in women. Obstet Gynecol. 2011;13:143-148. doi:10.1576/ toag.13.3.143.27665 
31. Miller JM, Ashton-Miller JA, DeLancey JO. A pelvic muscle pre-contraction can reduce cough-related urine loss in selected women with mild SUI. J Am Geriatr Soc. 1998;46(7):870-874.

32. McLean L, Varette K, Gentilcore-Saulnier E, Harvey M, Baker K, Sauerbrei E. Pelvic floor muscle training in women with stress urinary incontinence causes hypertrophy of the urethral sphincters and reduces bladder neck mobility during coughing. J Neurourol Urodyn. 2013;32(8):1096-1102.

33. Peschers U, Gingelmaier K, Leib B, Dimpfl T. Evaluation of pelvic floor muscle strength using four different techniques. Int Urogynecol J. 2001;12:27-30.

34. Bø K, Stien R. Needle EMG registration of striated urethral wall and pelvic floor muscle activity patterns during cough, valsalva, abdominal, hip, adductor and gluteal muscle contractions in nulliparous healthy females. J Neurourol Urodyn. 1994;13:35-41.

35. Sapsford R, Hodges P, Richardson C, Cooper D, Markwell S, Jull G. Co-activation of the abdominal and pelvic floor muscles during voluntary exercises. J Neurourol Urodyn. 2001;20 (1):31-42.

36. Laycock J, Haywood D. The place of physiotherapy in the management of pelvic floor dysfunction. Obstet Gynecol. 2003;5:194-199. doi:10.1576/toag.5.4.194.26931
37. Mørkved S, Bø K, Fjørtoft T. Effect of adding biofeedback to pelvic floor muscle training to treat urodynamic stress incontinence. Obstet Gynecol. 2002;100:730-739.

38. Newman D. Pelvic floor muscle rehabilitation using biofeedback. Urol Nurs. 2014;34(4):193-202.

39. Bø K, Talseth T, Holme I. Single blind, randomised controlled trial of pelvic floor exercises, electrical stimulation, vaginal cones, and no treatment in management of genuine stress incontinence in women. BMJ. 1999;318:487-493. doi:10.1136/bmj.318.7182.487

40. Herbison GP, Dean N. Weighted vaginal cones for urinary incontinence. Cochrane Database Syst Rev. 2002;(Issue 1). Art. No.: CD002114. doi:10.1002/14651858.CD002114.

41. Zanetti M, de Aqino Castro R, Lyvio Rotta A, Diniz dos Santos P, Sartori M, Girão M. Impact of supervised physiotherapeutic pelvic floor exercises for treating female stress urinary incontinence. Sao Paulo Med J. 2007;125(5):265-269. doi:10.1590/S1516-31802007000500003

42. Barbato K, Wiebe J, Cline T, Hellier S. Web-based treatment for women with stress urinary incontinence. Urol Nurs. 2014;34:252-258. doi:10.7257/1053-816X

43. Ali O, Tang T. Squeezy the NHS physiotherapy app for pelvic floor muscle exercises. Obstet Gynecol. 2016;18:74-74. doi:doi:10.1111/ tog. 12272
Research and Reports in Urology

\section{Publish your work in this journal}

Research and Reports in Urology is an international, peer-reviewed, open access journal publishing original research, reports, editorials, reviews and commentaries on all aspects of adult and pediatric urology in the clinic and laboratory including the following topics: Pathology, pathophysiology of urological disease; Investigation and

\section{Dovepress}

treatment of urological disease; Pharmacology of drugs used for the treatment of urological disease. The manuscript management system is completely online and includes a very quick and fair peer-review system, which is all easy to use. Visit http://www.dovepress.com/ testimonials.php to read real quotes from published authors. 